Jp.jok (Jurnal Pendidikan Jasmani, Olahraga dan Kesehatan)

http://ejurnal.budiutomomalang.ac.id/index.php/jpjok

Doi : https://doi.org/10.33503/jp.jok.v5i1.1730

\title{
Characteristics Of Physical Condition Of Futsal Athletes In Cianjur
}

\section{District}

\author{
Ge rry Kilat ${ }^{1)}$, Muhamad Syamsul Taufik ${ }^{2)}$, Awaluddin ${ }^{3)}$, Deden Akbar \\ Izzuddin $^{4)}$ Eneng Fitri Amalia ${ }^{5)}$ Muhamad Guntur Gaos Sungkawa') \\ ${ }^{1}$ Pendidikan Jasmani Kesehatan dan Rekreasi \\ 1,2,5,6 Universitas Suryakancana, Indonesia \\ ${ }^{3}$ Universitas Megarezky, Indonesia \\ ${ }^{4}$ Universitas Singaperbangsa Karawang, Indonesia
}

Email: ${ }^{1}$ Gerrykilat@ gmail.com, ${ }^{2}$ syamsul@unsur.ac.id, ${ }^{3}$ awaluddin@universitasmegarezky.ac.id,

ㄹden.akbar@fikes.unsika.ac.id, ${ }^{5}$ fitriamalia@unsur.ac.id, ${ }^{6}$ Gunturgs@unsur.ac.id

\section{ABSTRACT}

The purpose of this study was to determine the physical condition of futsal athletes in the Provincial Sports Week Qualification Round. The method used is descriptive quantitative with test and measurement techniques. The population consists of 16 Futsal Futsal Athletes in the Qualification Round of the Provincial Sports Week, and will then be used as research samples. The instrument used is a test and measurement of physical condition of Endurance, Power, Agility, Speed and Flexibility. Data analysis using T score. Based on the results of the analysis showed that the profile of physical condition in physical condition was in the good category with a percentage of $94 \%$ (15 people), in physical condition in the moderate category with a percentage of $6 \%$ (1 person). With an average of 17, the analysis of the physical condition of the BK Cianjur $B K$ futsal athletes in 2021 is in the good category. That the results of the analysis show that the profile of the physical condition of the futsal athlete BK Porda Cianjur Regency in 2021 is in a good category, so the coach advises the player to better maintain physical condition towards preparation for the Qualification Round of the Provincial Sports Week, so that the training program can be adapted to the athlete's physical condition. This requires a lot of programmed training to increase the physical condition of the players.

Keywords: Analysis, Physical Condition, Futsal

\section{Karakteristis Kondisi Fisik Atlet Futsal Kabupaten Cianjur Babak Kualifikasi Pekan Olahraga Provinsi}

\section{ABSTRAK}

Tujuan penelitian ini adalah untuk mengetahui kondisi fisik atlet futsal Babak Kualifikasi Pekan Olahraga provinsi. Metode yang digunakan adalah deskriftif kuantitatif dengan teknik tes dan pengukuran. Populasi ters ebut terdiri atas 16 Atlet Futsal futsal Babak Kualifikasi Pekan Olahraga provinsi.,dan selanjutnya akan dijadikan sampel penelitian. Instrumen yang digunakan adalah tes dan pengukuran Kondisi fisik Daya tahan, Power, Kelincahan, Kecepatan dan Kelentukan Analisis data menggunakan $\mathrm{T}$ score. Berdasarkan hasil analisis menunjukan bahwa profil kondisi fisik dalam kondisi fisik pada kategori baik dengan persentase $94 \%$ ( 15 orang), dalam kondisi fisik pada kategori sedang dengan persentase 6\% (1 orang). Dengan rata-rata 17, Analis is kondisi fisik atlet futsal BK porda cianjur tahun 2021 masuk ke dalam kategori baik. Bahwa Dengan hasil analis is tersebut menunjukan bah wa profil kondisi fisik atlet futs al BK porda kabupaten cianjur tahun 2021 dalam kategpri baik, sehingga bagi pelatih menyarankan pemain itu agar lebih mempertahankan kondisi fisik menuju persiapan Babak Kualifikasi Pekan Olahraga Provinsi, agar program latihan dapat disesuaikan dengan kondisi fisik atlet tersebut., sehingga perlu banyaknya latihan yang terprogramuntuk menambah kondisi fisik para pemain.

Kata kunci: Analisis, KondisiFisik, Futsal

(C) 2021 IKIP BUDI UTOMO MALANG

P-ISSN 2613-9421

E-ISSN 2654-8003
Info Artikel

Dikirim

Diterima

Dipublikasikan
- 7 Oktober 2021

: 20 November 2021

: 30 November 2021

Alamat korespondensi: syamsul@unsurac.id

Universitas Suryakancana, Jl. Pasirgede Raya, Bojongherang, Kec. Cianjur, Kabupaten Cianjur, Jawa Barat 43216, Indonesia 


\section{PENDAHULUAN}

Olahraga adalah aktivitas sekaligus kegiatan fisik. Olahraga telah sebagai bagian dari kegiatan masyarakat.(Rahadian et al., 2021) kegiatan ini umumnya dilakukan oleh seluruh ka langan mulai dari anak-anak, remaja, dewasa serta orang tua. Olahraga pula adalah kegiatan fisik yg memungkinkan tubuh manusia buat melakukan aktivitas sehari-hari.(Firdaus \&.Taufik,2020) syarat fisik merupakan prasyarat yang diperlukan untuk menaikkan prestasi seseorang atlet. Hal ini jua dapat digambarkan menjadi kebutuhan dasar yang tak bisa ditunda atau dinegosiasikan. olahraga dalam kehidupan sehari-hari keterampilan bermain futsalnya, terutama sehingga mampu meningkatkan kualitas dalam aspek teknik, fisik (Ilham \& Oktadinata, 2018) berdasarkan (Hendikawati, 2011) Keadaan fisik adalah unit komponen yang tidak dapat dipisahkan asal perspektif perbaikan dan pemeliharaan. Ini berarti Anda perlu menyebarkan semua komponen ini buat menaikkan syarat fisik Anda, namun memakai sistem prioritas tergantung pada kebutuhan dan status Anda buat membuatkan keterampilan, spiritualitas, dan strategi permainan Anda.semua komponen ini perlu ditingkatkan dan dikembangkan(Guntur Gaos, 2018). kondisi fisik ialah faktor penting dalam membuat pondasi atau pondasi.(Munandar et al., 2020) Komponen-komponen tersebut antara lain daya tahan (endurance), power (strength), kecepatan(speed), kelincahan(agility), serta kelentukan (flexcibility) (Bompa \& Buzzichelli, 2019).

Satu olahraga prestasi yg memerlukan penguasaan kondisi fisik yaitu futsal. (Nogueira et al., 2018) menyatakan bahwa kata futsal merupakan berasal negara Spanyol merupakan futbol serta sala yg artinya sepakbola didalam ruangan. Pada (Badaru, 2017) Perhatikan bahwa futsal ialah permainan bola yg dimainkan sang dua tim yg masing-masing beranggotakan 5 orang.(Tutus Eshananda Hars, Hermawan Pamot, 2014) Tujuannya artinya buat mengontrol bola menggunakan kaki Anda serta memasukkannya ke gawang versus.(Syaroni et al., 2020) Pentingnya Kondisi fis ik dalam permainan futsal karena dalam permainan futsal yang paling penting dan kemampuan teknik dasar dikuasai perlu latihan yang sungguh-sungguh dan direncanakan dengan baik dan di dukung karena itu dengan kondisi fisik yang baik.(Irawan, 2020) Kondisi fisik pemain dapat dipantau dalam latihan yang dilakukan oleh pelatih, maka pentingnya kondisi fisik tekanan harus 
diberikan pada perkembangan tubuh secara terukur dan teratur dengan memperhatikan tingkatan pemain (Dwi Priyono, Fransiskus Nurseto, Suwarli, 2020). bahwa kondisi fisik adalah salah satu syarat yang sangat diperlukan dalam usaha peningkatan prestasi seorang atlet (haripah lawanis, suci nanda sari, 2019), bahkan sebagai ladasan titik tolak suatu awalan olahraga prestasi. (Danarstuti Utami, 2015) Karena kalau seorang pemain futsal memiliki kemampuan fisik yang kurang bagus akan sangat berpengaruh dalam pertandingan jika kemampuan fisiknya tidak bagus akan berpengaruh ke kemapuan yang lain. (Puriana, 2019) perlunya peningkatan kondisi fisik dan teknik khususnya kemampuan untuk menunjang teknik karena terlihat ketika saat bertanding (Munandar et al., 2020) Futsal merupakan salah satu olahraga futsal mudah ditemukan terutama terpopuler di Indonesia saat ini bahkan dimainkan oleh anak anak yang merupakan sudah bisa menyaingi olahraga sepakbola. cikal bakal pemain futsal masa depan Futsal merupakan olahraga semua lapisan Indonesia(Hasibuan, 2019).

Sesuai uraian pada atas, syarat fisik artinya dasar buat mencapai prestasi yang aporisma, serta kondisi fisik pema in futsal Babak Kualifikasi Pekan olahraga provinsi Porda Cianjur masih dipertanyakan. oleh sebab itu, pada tahun 2021 dilakukan survei sang tim Babak Kualifikasi Pekan Olahraga Probinsi di Kabupaten Cianjur Pada cabang olahraga Futsal berdasarkan (Varkiani et al., 2013) menyatakan futsal bisa menggunakan simpel didefinisikan yang cepat dan taktis maka perlu dengan keadaan Pemain yang prima dalam setiap pertandingan. Oleh karena itu membutuhkan tingkat daya tahan yang baik dikarenakan olahraga membutuhkan intensitas tinggi sehingga pemain futsal perlu dengan pendukung kondisi fisik yang baik(Syahrul, 2014). berdasarkan latar belakang di atas, maka penulis mengajukan Melihat bagaimana kondisi fisik Atlet Futsal Kabupaten Cianjur Pada Babak Kualifikasi Pekan Olahraga Provinsi

\section{METODE}

Metode survei yg dipergunakan pada survei ini adalah metode kuantitatif yg menggunakan jenis survei tes dan pengukuran untuk mengetahui syarat fisik Babak Kulifikasi Pekan Olahraga Provinsi pemain futsal di Kabupaten Cianjur. Penggunaan metode penelitian ini harus mengarah pada tujuan yang diperlukan dan dapat dipertanggung jawabkan secara ilmiah. survei ini bertujuan buat 
menjelaskan kondisi fisik pemain futsal dari Babak Kualifiikasi Pekan Olahraga Provinsi di Kabupaten Cianjur di tahun 2021.

Rancangan yang digunakan pada penelitian ini terdiri dari pengujian dan pengukuran. Survei ini artinya survei deskriptif. Populasi terdiri dari 16 atlet futsal Babak Kualifikasi Pekan Olahraga Provinsi dijadikan sampel penelitian. Metode pengumpulan data dalam penelitian ini memakai teknik tes serta pengukuran. dalam penelitian ini, peralatan yang digunakan buat mengumpulkan data terdiri asal lima item tes yaitu Daya tahan aerobic (multy stage test) menggunakan satuan $\mathrm{ml} / \mathrm{kg} / \mathrm{min}, 2$. Power (vertical jump) dengan satuan $\mathrm{cm}, 3$. Kelincaahan (illionis agility run test) dengan satuan detik, 4. Kecepatan (lari 30 meter) dengan satuan detik, 5. Fleksibilitas atau kelentukan (sit and rich) denan satuan cm. pendataan kondisi fisik atlet futsal Babak Kualifikasi Pekan Olahraga Provinsi cabang Olahraga futsal memakai tes serta pengukuran. Analisis data berasal penelitian ini menggunakan Data Analisi Deskripsi.

\section{HASIL DAN PEMBAHASAN}

\begin{tabular}{lllllll}
\hline & N & Sangat Baik & Baik & Cukup & Sedang & Kurang \\
\hline Daya tahan & 16 & $0 \%$ & $16 / 100 \%$ & $0 \%$ & $0 \%$ & $0 \%$ \\
Power & 16 & $13 / 81 \%$ & $3 / 19 \%$ & $0 \%$ & $0 \%$ & $0 \%$ \\
Kelincahan & 16 & $0 \%$ & $0 \%$ & $81 \%$ & $0 \%$ & $0 \%$ \\
Kecepatan & 16 & $81 \%$ & $19 \%$ & $0 \%$ & $6 \%$ & $0 \%$ \\
Kelentukan & 16 & $6 / 38 \%$ & $4 / 38 \%$ & $6 / 25 \%$ & $0 \%$ & $0 \%$ \\
\hline
\end{tabular}

Data yang diperoleh dari setiap item tes adalah data kasar berasal hasil setiap tes yg diperoleh atlet. selesainya data diubah menjadi data diinterpretasikan menggunakan mengklasifikasikan data, serta pembagian terstruktur mengenai tersebut dikelompokkan sebagai lima kategori: sangat baik, baik, sedang, cukup, dan sedikit.Setelah melakukan tes penelitian, data yang diperoleh mela lui tes dan pengukuran memakai item tes dan pengukuran, data penelitian inni terdiri atas :

\begin{tabular}{cclr}
\hline Interval & Absolut & Kategori & Presentasi \\
\hline $25-20$ & 0 & Sangat Baik & $0 \%$ \\
$19-15$ & 15 & Baik & $94 \%$ \\
$14-10$ & 1 & Sedang & $6 \%$ \\
$9-5$ & 0 & Cukup & $0 \%$ \\
$4-0$ & 0 & Kurang & $0 \%$ \\
\hline
\end{tabular}

Hasil Distribusi frekuensi kondisi fisik (T score) 
Berdasarkan tabel diatas terlihat bahwa yang akan terjadi keseluruhan profil syarat fisik atlet futsal BK porda kabupaten cianjur tahun 2021 berada pada kategori baik dengan jumlah 15 orang atlet presentase 94\%, lalu pada kategori sedang dengan jumlah atlet 1 orang dengan presentase $6 \%$ maka menjadi berikut: ditampilkan pada bentuk diagram btg, hasil analisis data, penjelasan, survey, dan pembahasan dapat disimpulkan profil kondisi fisik atlet BK Polda Kabupaten. Berdasarkan hasil analisis Cianjour tahun 2021 menunjukkan bahwa profil kondisi fisik sangat baik sebesar 0\% (0 orang), dan kondisi fisik dalam kategori baik sebesar 94\% (15 orang). kategori sedang sebesar 6\% (1 orang), pada kategori sedang sebesar $0 \%$ (0 orang), dan pada subkategori 0\% (0 orang). Dengan ratarata 17, analisis kondisi fisik Atlet Futsal BK Cianjur 2021 berada dalam kategori baik. Pelatih diharapkan dapat menjaga dan meningkatkan kondisi fisiknya. Pelatih perlu mengetahui atlet mana yang perlu ditingkatkan untuk meningkatkan teknik mereka dan seterusnya. Pelatih perlu menyadari faktor-faktor yang perlu ditingkatkan oleh atlet. Atlet harus dapat mempertahankan latihan dan pelatihan diet untuk lebih mendukung kondisi fisik terbaik mereka. Untuk mencapai prestasi terbaik Data tampak di gambar di bawah ini.

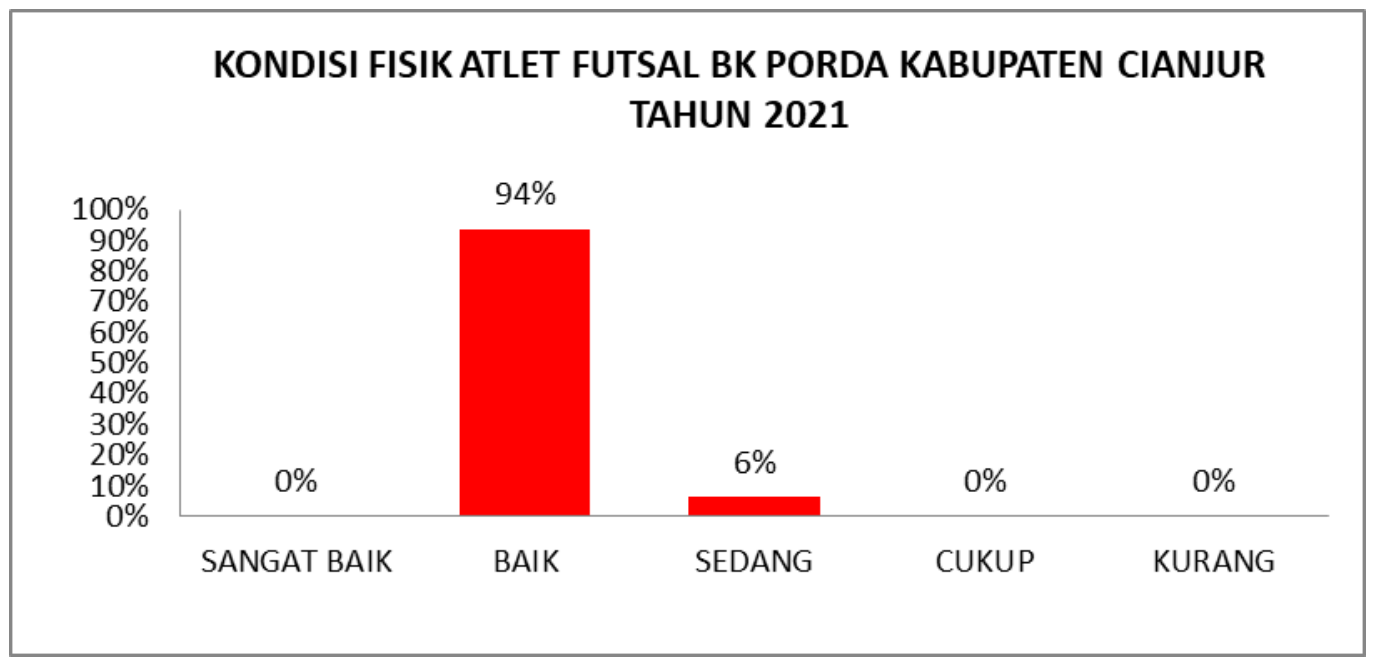

Gambar 1 Diagram Batang Frekuensi Kondisi Fisik.

Setelah dilakukan survey untuk menganalisis kondisi fisik atlet futsal di Babak Kualifikasi Pekan Olahraga Daerah Provinsi Cabang Olahraga futsal. Dari hasil analisis data, penjelasan, survey, dan pembahasan dapat disimpulkan profil kondisi fisik futsal, para atlet perlu saling mendorong untuk mempertahankan dan 
meningkatkan latihannya agar kondisi fisiknya berada pada kategori sangat baik. Tujuan dari penelitian ini adalah untuk mengetahui profil kondisi fisik pemain futsal Babak Kualifikasi Pekan Olahraga provinsi Polda Cianjur 2021 Dengan rata-rata 17, analis is kondisi fisik Atlet Futsal Babak Kualifikasi Pekan Olahraga provinsi Cianjur 2021 berada dalam kategori baik. Berdasarkan hasil analisis, profil kondisi fisik atlet futsal Babak Kualifikasi Pekan Olahraga provinsi 2021 berada pada kategori baik dengan pangsa 94\% (15 orang), memungkinkan pelatih untuk menyesuaikan atihan lebih baik dengan kondisi fisik atlet. Sama dengan hasil penelitian sebelum nya yaitu penelitian nya adalah buat mengetahui profil kondisi fisik atlet PORPROV futsal Kabupaten Bangkalan tahun 2019. Selain buat dasar memberikan porsi latihan, hal ini bisa dipergunakan pula buat mencari solusi yg sempurna untuk mengatasi konflik kondsi fisik yg terjadi(Anwar, 2019)

Futsal menuntut syarat fisik yang prima bagi para pemainnya. Kemudian pendapat penelitian (Yusuf \& Zainuddin, 2020) syarat fisik yangprima sangatlah menunjang penampilan seorang pemain. Penampilan fisik yg buruk tentunya akan berdampak buruk pula bagi penampilan teknik dan taktiknya. Persiapan fisik adalah suatu hal yg krusial dalam masa persiapan sebuah tim untuk mencapai prestasi yg optimal. Kampus UNDIKMA artinya galat satu kampus partikelir yang ada pada Provinsi Nusa Tenggara Barat yg mempunyai fakultas olahraga serta kesehatan dan kawasan pembinaan at lit futsal UNDIKMA kemudian dengan Kondisi fisik adalah suatu komponen fisik yang sangat penting hampir di semua olahraga. Futsal adalah permainan yang mirip sepakbola dan memliki tujuan membuat gol untuk mendapatkan sebuah kemenangan. Penelitian ini membahas tentang permasalahan kondisi fisik atlet futsal Lumajang. Tujuanuntuk mengetahui kondisi fisik atlet futsal putra Kabupaten Lumajang untuk persiapan Porprov VII tahun 2022 yang meliputi; Daya Tahan, Daya Tahan Otot, Fleksibilitas dan Kekuatan.(Ramadiansyah et al., 2022)

Selain itu, tetap jaga kebugaran untuk mempersiapkan babak kualifikasi pekan olahraga provinsi. Jika kategori baik, dapat ditingkatkan lagi ke kondisi sangat baik, mencapai kinerja maksimal dan mengalami perubahan, dan mencapai kinerja terbaik sampai menerapkan. Sesuai dengan pendapat dari penelitian ini adalah untuk mengetahui kebutuhan komponen fisik atlet futsal putra, kondisi 
fisik atlet meliputi tingkat daya tahan, kecepatan, kelincahan, kekuatan ot ot tungkai, dan daya ledak otot tungkai.(Wahyu et al., 2019) Berdasarkan penelitian sebelumnya tentang profil kondisi fisik diatas, penelitian ini tergolong rendah, sehingga kami menambahkan waktu khusus untuk pelatih dan pemain itu sendiri untuk melakukan latihan yang berkaitan dengan kondisi fisik mereka. hasil untuk mencapai kondisi fisik Anda. Studi menunjukkan bahwa pemain futsal Kabupaten Futsal Cianjur masih dalam kondisi moderat untuk Pekan Olahraga Daerah dan membutuhkan banyak latihan terprogram untuk memperbaiki kondisinya. Dari ketiga hasil di atas dapat kita lihat bahwa penelitian yang saya lakukan memberikan referensi yang cukup dan terdapat perbedaan hasil kategori hasil survei.

\section{SIMPULAN}

Bahwa Dapat disimpulkan dengan hasil penelitian menandakan bahwa profil syarat fisik atlet futsal Menuju Babak Kualifikasi Pekan olahraga provinsi porda kabupaten cianjur tahun 2021 di kategpri baik menjadi akibatnya bagi instruktur menyarankan pemain itu agar lebih mempertahankan kondisi fisik menuju persiapan Babak Kualifikasi Pekan Olahraga Provinsi Cabang Olahraga futsal porda, supaya acara latihan mampu disesuaikan dengan kondisi fisik atlet tadi.pemain futsal Kabupaten Futsal Cianjur..

\section{DAFTAR RUJUKAN}

Anwar, K. (2019). Profil Kondisi Fisik Atlet Porprov Futsal Kabupaten Bangka lan Tahun 2019. Jurnal Kejaora (Kesehatan Jasmani Dan Olahraga), 4(2), 1-5. Https://Doi.Org/10.36526/Kejaora.V4i2.678

Badaru, B. (2017). Latihan Taktik Beyb Bermain Futsal Modern. Cakrawala Cendekia.

Bompa, T. O., \& Buzzichelli, C. A. (2019). Peridization: Theory And Methodology Of Training. In Journal Of Chemical Information And Modeling (Vol. 53, Issue 9).

Danarstuti Utami. (2015). Peran Fis iologi Dala m Meningkatkan Prestasi Olahraga Indonesia Menuju Sea Games Danarstuti. Olahraga Prestasi, 11(2), 52-63.

Dwi Priyono, Fransiskus Nurseto, Suwarli, A. C. (2020). Performa Kondisi Fisik 
Atlet Pelatprov Provinsi Lampung Menuju PON Papua 2020. Jurnal Olympia, $4(2)$ $1-6$.

Http:/Journal.Binadarma.Ac.Id/Index.Php/Olympia\%0aperforma

Firdaus , MS.Taufik, A. A. (2020). Analisis Kebiasaan Merokok Terhadap Pencapaian Pembelajaran Mata Pelajaran Di Sekolah. Jurnal Altius: Jurnal Ilmu Olahraga Dan Kesehatan,9(1), 64-72.

Guntur Gaos, M. (2018). Model Latihan Stre ngth Untuk Panjat Tebing Pada Atlet Usia Remaja. Maenpo, 8(1), 14. Https://Doi.Org/10.35194/Jm.V8i1.913

Haripah Lawanis, Suci Nanda Sari, F. (2019). Tinjauan Kondisi Fisik Atlet Hockey. Journal Performa, 4(1), 2019.

Hasibuan, M. H. (2019). Pengembangan Model Latihan Passing Dan Receiving The. Gladi Jurnal, 5(1), 217-240.

Hendikawati, P. (2011). Analis is Faktor Yang Mempengaruhi Indeks Prestasi Mahasiswa. Kreano: Jurnal Matematika Kreatif-Inovatif. Https://Doi.Org/10.15294/Kreano.V2i1.1243

Ilham, W. J. D., \& Oktadinata, A. (2018). Sosialisasi Dan Coaching Clinic Teknik Dasar Futsal Pada SMP N 11 Kota Jambi. Jurnal Cerdas Sifa, 1(2), 9-15.

Irawan, A. (2020). Jurnal Ilmiah Sport Coaching And Education Vol . 4 Juli 2020 Profil Kondisi Fisik Tim Futsal Liga Mahasiswa Universitas Negeri Jakarta 2019.4.

Munandar, A., Taufik, M. S., \& Putri, R. E. (2020). Pengaruh Latihan Plyometrics Otot Tungkai. Jurnal Maenpo : Jurnal Pendidikan Jasmani Kesehatan Dan Rekreasi, 10,1-6.

Nogue ira, F. C. D. A., De Freitas, V. H., Nogueira, R. A., Miloski, B., Werneck, F. Z., \& Bara-Filho, M. G. (2018). Mejora Del Rendimiento Físico, Perfil Hormonal, Balance Estrés-Recuperación Y Aumento Del Daño Muscular Basado En La Planificación Específica De Pretemporada En El Fútbol Sala. Revista Andaluza De Medicina Del Deporte, 11(2), 63-68. Https://Doi.Org/10.1016/J.Ramd.2015.11.008

Puriana, R. H. (2019). Pengaruh Latihan Small Sided Games 3v3 Dan 4v4 Terhadap Peningkatan Vo2max Atlet Futsal Putra Di Lamongan. Jurnal Pendidikan Jasmani, 2(1), 187-191.

Rahadian, A., Ma'mun, A., Berliana, \& Nuryadi. (2021). 2018 Asian Games Success : Polic ies For The Development Of Indonesian Elite Athlete. Jurnal Maenpo: Jurnal Pendidikan Jasmani Kesehatan Dan Rekreasi, 11(3), 1-12.

Ramadiansyah, Y. A., Olahraga, P. K., Olahraga, F. I., \& Surabaya, U. N. (2022). Analisis Kondisi Fisik Atlet Futsal Lumajang Pada Persiapan Porprov 2022 
Yanuar Ahmad Ramadiansyah.

Syahrul. (2014). Evaluasi Kemampuan Kondisi Fisik Dominan Pada Atlit Pencak Silat Perguruan Gerak Ilham Kabupaten Aceh Besar Tahun 2014. Penjaskesrek Journal, I, 2.

Syaroni, F. D., Made, I. D., \& Wijaya, A. (2020). Vo2max Pada Siswa Ekstrakurikuler. 3(1), 1-5.

Tutus Eshananda Hars, Hermawan Pamot, R. (2014). Journal Of Physical Education, Sport, Health And Recreations. Journal Of Physical Education, Sport, Health And Recreation, 4(2), 102-108. Http://Journal.Unnes.Ac.Id/Sju/Index.Php/Peshr

Varkiani, M. E., Alizadeh, M. H., \& Pourkazemi, L. (2013). The Epidemiology Of Futsal Injuries Via Sport Medicine Federation Injury Surveillance System Of Iran In 2010. Procedia - Social And Behavioral Sciences, 82, 946-951. Https://Doi.Org/10.1016/J.Sbspro.2013.08.001

Yusuf, P. M., \& Zainuddin, F. (2020). Survei Kondisi Fisik Kelincahan Pemain Futsal Undikma. Jurnal Ilmiah Mandala Education, 6(1), 2019-2021. Https://Doi.Org/10.36312/Jime.V6il.1123 